AL. $2.1997-315$ C. 2

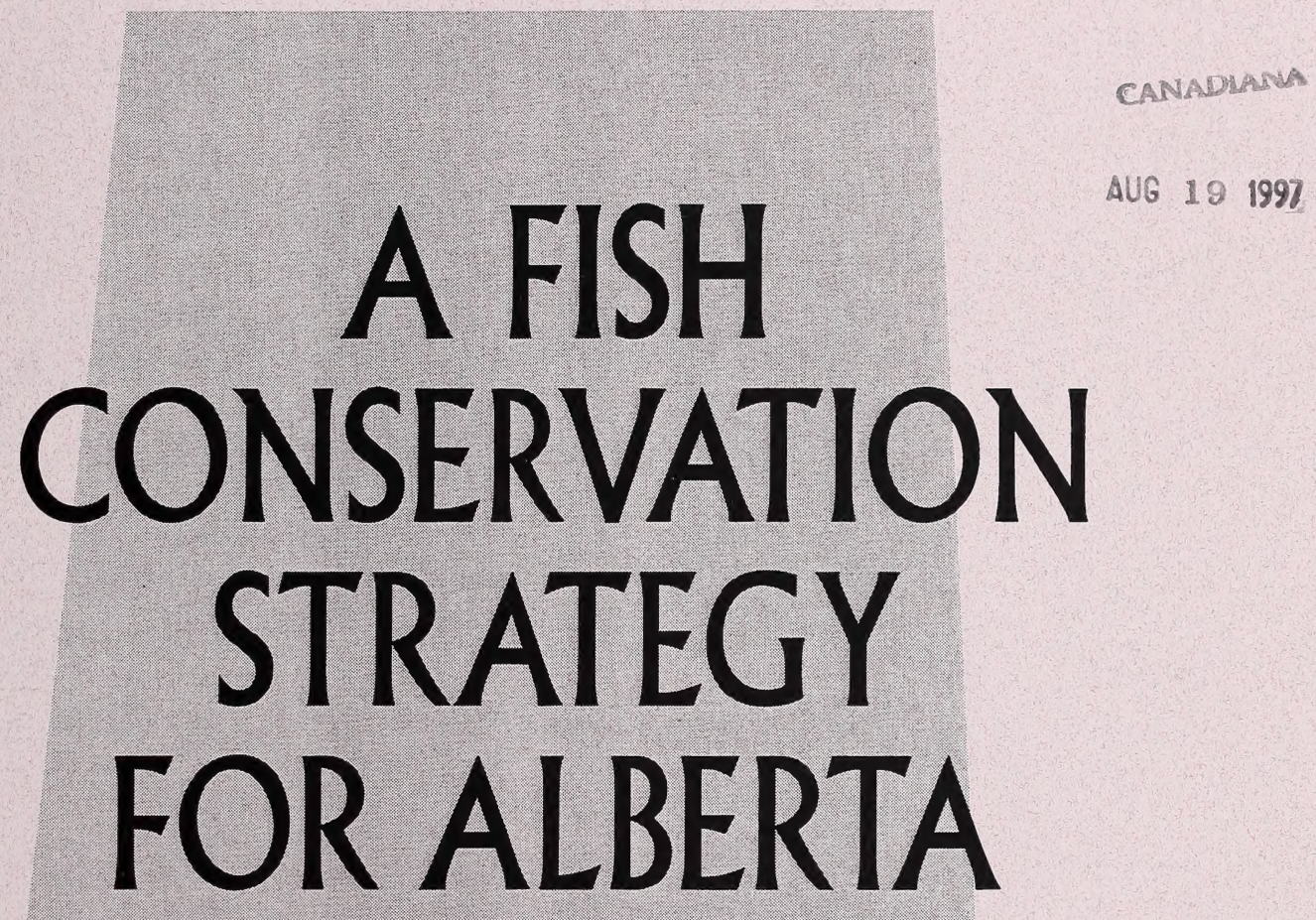

$1997-2005$

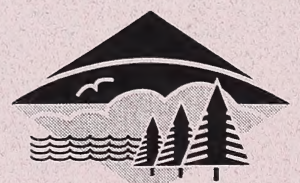




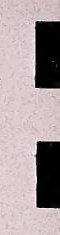

I

I

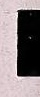

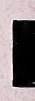

I

,

,

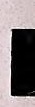

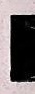

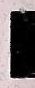

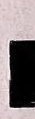

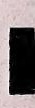

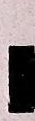

\

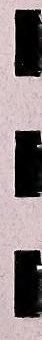




\section{A FISH}

\section{CONSERVATION STRATEGY \\ FOR ALBERTA}

$1997-2005$ 
Pub. No.: $1 / 640$

ISBN: 0-7732-5097-2

Date: May 1997
Interim printing for distribution to staff of the Fisheries Management Division. This document is also being printed in booklet and brochure formats for public distribution. For copies of the booklet and brochure, please contact:

\section{Fisheries Management Division Natural Resources Service Alberta Environmental Protection 9945-108th Street Main Floor Edmonton, Alberta T5K 2 G6}




\section{TABLE OF CONTENTS}

1.0 Introduction

2.0 Resource Stewardship

3.0 Mission Statement of Fisheries Management Division.......

4.0 Benefits from Fish Resources

5.0 Jurisdiction for Management of Fish Resources

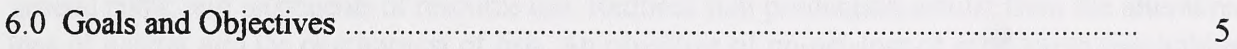

6.1 Habitat Maintenance Goal ............................................................................ 5

6.1.1 Habitat Maintenance Objectives............................................................. 5

6.1.1.1 Fish Habitat Protection .............................................................. 5

6.1.1.2 Fish Habitat Rehabilitation ........................................................ 6

6.1.1.3 Fish Habitat Development .......................................................... 6

6.1.2 Integrated Resource Management ...................................................... 7

6.2 Fish Conservation Goal ................................................................................. 7

6.2.1 Fish Conservation Objectives.................................................................. 8

6.2.1.1 Fish Production Maintenance .......................................................... 8

6.2.1.2 Fish Production Restoration ....................................................... 8

6.2.1.3 Fish Production Enhancement and Development ........................ 8

6.2.2 Fish Production Management ......................................................... 8

6.3 Fish-Use Allocation Goal ................................................................................ 9

6.3.1 Fish-Use Allocation Objectives............................................................. 10

6.2.1.1 Fish-Use Allocation Process .................................................. 10

6.2.1.2 Domestic Use ................................................................... 11

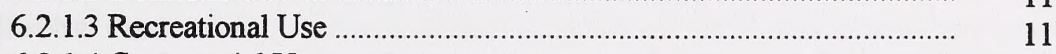

6.2.1.4 Commercial Use ................................................................... 11

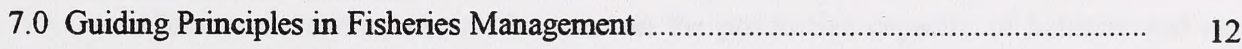

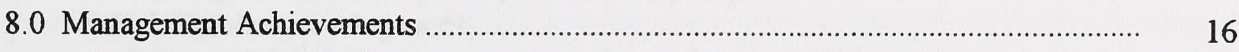

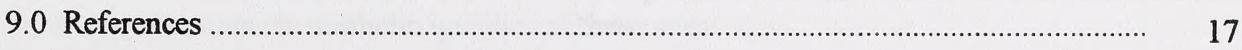


"Resource stewardship, although a mandate of government, is the responsibility of everyone---the general public and proponents of resource use." 


\section{EXECUTIVE SUMMARY}

A Fish Conservation Strategy for Alberta has been developed to guide the management of fish resources in a manner consistent with the Fisheries Act of Canada, the Fish and Wildlife Policy for Alberta, and the business plans of Alberta Environmental Protection and Natural Resources Service. The first purpose of the Fisheries Act is to conserve and protect fish and fish habitat. The Fish and Wildlife Policy recognizes fish conservation as the first priority and establishes the Fish and Wildlife Division [Natural Resources Service] as the advocate within government for resource stewardship. Providing a healthy environment by sustaining the biodiversity, productivity, structure and functions of its ecosystems is supported by the business plans of the department and service. The mission statement for the Fisheries Management Division is:

\section{"Sustain the abundance, distribution and diversity of fish populations at the carrying capacity of their habitats."}

Resource stewardship, although a mandate of government, is the responsibility of everyone--the general public and proponents of resource use. Reduced fish production results from the alteration or loss of habitat and the overharvest of fish. An objective of no-net-loss of productive fish habitat is endorsed as a working guideline in decision making. Fish habitat has to be protected and where mitigative procedures can not eliminate habitat losses, then fish habitat compensation is important. A policy is also needed to control the harvest of fish, and to require proof that a harvestable surplus exists before harvest is permitted.

Conservation of the fish resources can not be achieved through control of fish harvest alone. Fisheries Management Division must advocate the integration of habitat maintenance into the goals of other natural resource users. Habitat protection, habitat mitigation and water quality need to be treated by all resource users as essential components of resource management planning. To fully achieve the fish conservation strategy, water-use legislation and policy has to recognize fish as a user of water and incorporate the needs of fish into water resource management.

The following goals and objectives, detailed in section 6.0, are required in fisheries management:

1. Habitat maintenance goal (section 6.1):

"Restore and maintain the productive capacity of fish habitat, and where possible and appropriate, increase the amount of productive fish habitat."

a) Fish Habitat Protection

-Maintain the productive capacity of habitats to support healthy and diverse fish resources.

b) Habitat Rehabilitation

-Alleviate or reverse adverse impacts on the productive capacity of habitats and repair damaged habitats to restore productive capacity.

c) Fish Habitat Development

-Enhance fish habitats in areas where the production of fish resources can be increased and maintain the aesthetic qualities of these sites.

2. Fish conservation goal (section 6.2):

"Restore and maintain the abundance, distribution and diversity of fish through natural reproduction."

a) Fish Production Maintenance

-Maintain the abundance and diversity of fish at the carrying capacity of the habitat. 
b) Fish Production Restoration

-Restore diminished fish production to full production wherever possible.

c) Fish Production Enhancement and Development

-Enhance or develop new fish production wherever appropriate and possible.

3. Fish-use allocation goal (section 6.3):

"Allocate, through a public involvement process, the appropriate use or combination of uses of fish resources to achieve a range of benefits that support the fish conservation goal."

a) Fish-Use Allocation Process -Allocate fish production, beyond conservation needs, to achieve greatest overall benefits.

b) Domestic Use

-Provide for subsistence fishing within the constraints of fish conservation and legislative obligations.

c) Recreational Use

-Provide for recreational fishing under an open-access policy and place no limitation on the number of general licences issued, within the constraints of fish conservation and subsistence fishing.

d) Commercial Use

-Provide for commercial fishing opportunities within the constraints of fish conservation, subsistence fishing and recreational fishing.

There are several guiding principles outlined in section 7.0 that can assist in the implementation of the overall fish conservation strategy. They are:

1. No net loss of the productive capacity of habitats.

Every effort should be made to avoid habitat losses. If habitat losses are unavoidable, they should be balanced with habitat replacement.

2. Fish populations are to be maintained by natural reproduction wherever possible. Natural reproduction is the most biologically sound and cost-effective way of maintaining fish populations and fish production.

3. The biological diversity of the fish fauna is to be maintained, and the depletion or extirpation of species, populations, sub-populations or unique strains must be avoided. Any maintenance and protection strategy should include all fish species in order to maintain the biological diversity of the fish fauna.

4. The management of the fisheries will be based on fundamental ecological principles and factual information.

Good and timely information on fish stocks (including their number, growth, production rate, harvest rate and habitat conditions) is fundamental to achieving habitat maintenance, fish conservation and fish-use allocation goals.

5. There should be public involvement and education in the fisheries management process. Greater public awareness and the involvement of a knowledgeable public are essential to increase public support for fisheries management.

6. The "user-pays philosophy" should augment the financing of the stewardship and management of fish resources.

The responsibility for financing the stewardship of fish resources must be shared by all, and be augmented by fees and levies paid by resource users such as fishermen, resource developers and industries.

7. Public access should be provided and maintained to waters producing publicly-owned fish. Unencumbered access to waters producing publicly-owned fish is a prerequisite to using fish resources for public benefits. 


\subsection{INTRODUCTION}

Alberta has a wide range of aquatic habitats--from small streams in the mountains and foothills to large rivers extending through the prairie, parkland and boreal regions; and from alpine lakes, prairie potholes and reservoirs to large lakes of the northern boreal forest. These aquatic systems contain a diverse fish fauna made up of 60 species, of which 51 are native and 9 have been introduced. Eighteen species are important in recreational, commercial or domestic fisheries. The remaining 42 species, the majority of which are small in size, are indices of biodiversity and play an important role in the food chain for predatory fish and fish-eating birds and mammals. Brook trout, brown trout and golden trout, although introduced species, have established self-reproducing populations and have become integral components of the game fish fauna of Alberta. The distributions of native species such as rainbow trout, cutthroat trout, walleye, lake whitefish, yellow perch and northern pike have been expanded through stocking and transfers, and the subsequent development of self-reproducing populations in new areas.

The fish resources of Alberta are limited in abundance by the small amount of suitable habitat. Alberta does not have a large amount of surface water, having only 2.5 percent of its area as freshwater. Surveys conducted on over 2100 lakes have shown that only about 1030 have game fish producing capabilities. The other lakes are too shallow and either freeze to the bottom during winter or are too warm for fish during summer. By comparison, Saskatchewan has an estimated 94 000, Manitoba has 110000 and Ontario has 250000 fish-bearing lakes. While Saskatchewan, Manitoba and Ontario each have a ratio of about two anglers per lake, Alberta's ratio is closer to 250 anglers per lake. Approximately 3/4 of the lake area in Alberta is located north of a line through Lac La Biche and Valleyview, whereas about $3 / 4$ of the human population lives in the area south of that line. This results in very high demand placed on the fish resources in the settled part of the province. Fish populations in Alberta have declined as a result of overharvest and habitat alteration.

Interest in natural history and the publics environmental values concerning the importance of fish resources have emerged in addition to increased demand for recreational and food uses of fish resources. Public interest in fish, their habits and their aquatic environments, in viewing fish, and in simply knowing they exist and are managed, is growing with increasing environmental awareness. Furthermore, healthy, uncontaminated fish are indicators of a healthy aquatic environment. Industrial and resource development have cumulative effects on the quality of the aquatic environment, fish production and fish health.

The following document outlines the fish conservation strategy that has been adopted for the management of fish resources in Alberta. This document is based on an earlier discussion paper, $A$ Fish Conservation Strategy for Alberta, prepared in 1990. A companion document, The Fish and Fisheries of Alberta: Facts and Figures (Berry 1990) provides supporting information on fish resources in Alberta. The fish conservation strategy for Alberta is consistent with the business plans of the department (Alberta Environmental Protection 1996) and the service (Natural Resources Service 1996), as well as The Fish and Wildlife Policy for Alberta (Fish and Wildlife Division 1982). 


\subsection{RESOURCE STEWARDSHIP}

Inherent in the stewardship of the resource is the responsibility to conserve fish populations to maintain the natural biodiversity and health of aquatic ecosystems. This responsibility is reflected in the business plan of the department (Alberta Environmental Protection 1996) and of the service (Natural Resources Service 1996), as follows:

\section{Mission Statement of Alberta Environmental Protection}

As proud stewards of Alberta's renewable natural resources, we will protect, enhance and ensure the wise use of our environment. We are a dedicated and committed team, responsible for managing those resources with Albertans. We are guided by a shared commitment to the environment and are accountable to our partners, the people of Alberta.

\section{Vision Statement of Natural Resources Service}

Healthy environment and sustainable resources supporting a healthy economy and a high quality of life.

Conservation includes two components: 1) protection which ensures the perpetuation of abundant fish populations, and 2) the appropriate use of only the surplus that is not required for population maintenance. Fish resources must be managed to meet the requirements of present users without compromising the ability of future generations to meet their needs. The mandate for Natural Resources Service is expressed in the document The Fish and Wildlife Policy for Alberta (Fish and Wildlife Division 1982), as follows:

\section{Fisheries Policy [Mandate]}

Fisheries is a replenishable Crown resource; it is incumbent upon the Government, as the resource steward, to ensure that appropriate use is made of the fisheries resource and that it is passed on to succeeding generations as it was received. The primary consideration of the Government is to ensure that fisheries populations are protected from severe decline and that viable populations are maintained. By virtue of the fact that all fish and wildlife resources and relevant legislation are the responsibility of the Fish and Wildlife Division [Natural Resources Service], it is to function as the advocate within government in the pursuit of this goal. 


\subsection{MISSION STATEMENT OF FISHERIES MANAGEMENT DIVISION}

Biodiverse and productive ecosystems maintain healthy fish populations and support social and economic benefits for Albertans. The mission statement of fisheries management, in line with the mission, vision and policy statements provided above, is as follows:

\section{Mission Statement of Fisheries Management Division}

Sustain the abundance, distribution and diversity of fish populations at the carrying capacity of their habitats.

The following are three primary components of the above mission statement for fisheries management:

- HABITAT MAINIENANCE--sustain, or achieve a net gain in, the quality and quantity of fish habitat;

- FISH CONSERVATION--regulate fish harvest in line with, and not exceeding, the productive capacity of fish populations; and

- FISH-USE ALLOCATION--manage fish populations in a manner that meets the present expectations of Albertans without compromising the ability of future generations to meet their expectations.

\subsection{BENEFITS FROM FISH RESOURCES}

The benefits Albertans expect from their fish resources are diverse and include both consumptive and non-consumptive values. These include:

\section{- An indicator of the quality of the aquatic environment.}

Fish populations are sensitive. Healthy, uncontaminated fish populations are indicators of a healthy aquatic environment. The quality of the water and aquatic habitat are important to anglers and nonanglers.

\section{- A source of recreational opportunities.}

The sportfishery, which includes many techniques, philosophies and interests, is a significant form of outdoor recreation and a major user of fish resources. However, the overall recreational experience of sportfishing is strongly related to healthy aquatic environments. Anglers responding to surveys consistently indicate the lack of pollutants in fish, water quality and natural beauty of the area as the most important factors when choosing a fishing destination.

\section{- A source of food.}

Fish are still an important source of food for participants in the domestic and recreational fisheries, and for people who purchase fish from the commercial fishery. There is a continuing concern about the level of contamination by various metals and chemicals, and about the quality of fish for food.

\section{- A source of economic opportunities.}

Annual expenditures associated with the recreational fishery generally exceed $\$ 335$ million for goods, services and major investments, and annual sales of commercially caught fish exceed $\$ 3$ million. 


\section{- A source of natural history interests.}

Public interest in fish, their habits and their aquatic environments, in viewing fish, and in simply knowing they exist and are managed, is growing with increasing environmental awareness.

- A source of scientific and research opportunities.

Research provides methods to achieve a better understanding of the nature of fish, the production capabilities of their habitats, and ways to protect fish populations and their habitats from human activities.

\subsection{JURISDICTION FOR MANAGEMENT OF FISH RESOURCES}

The Constitution Act (1982) [British North American Act (1867)], in establishing the authority of parliament, gave the federal government the responsibility for all seacoast and inland fisheries. This responsibility involves control of how many fish may be harvested, when fish may be harvested, what type of fishing gear may be used, and the protection of habitat to ensure fish production in perpetuity.

When responsibility for the management of natural resources was transferred to the province (Natural Resources Transfer Agreement 1930), stewardship became a shared responsibility. Under British common law, fish are considered a product of the land under the water. With few exceptions, land under water in Alberta is owned by the province (Section 3, Public Lands Act, Revised Statutes of Alberta, P-30). This ownership of, or proprietary right to fish gives the province the authority and responsibility to determine who can take fish, as well as where and when they can fish, and what disposition is made of the fish after they have been caught.

Two regulation-making processes exist to fulfil provincial responsibilities for managing fish resources. Most fishery regulations are implemented through the federal Fisheries Act of Canada and the pursuant Alberta Fishery Regulations. The province manages the fish resources and the federal government facilitates legislative changes as recommended by the province. Additional regulations have been implemented through the provincial Fish Marketing Act. Proclamation of a Fisheries (Alberta) Act and pursuant regulations in 1997 will give a provincial bases for the licensing system and increase the ability to implement regulation changes in a shorter time frame than through the current federal amendment process. Greater provincial responsibility for the fish resource would occur if the transfer of additional regulation-making authority from federal to provincial jurisdiction is completed.

\section{"...the habitat goal is the foundation of the fish conservation strategy..."}




\subsection{GOALS AND OBJECTIVES}

Achieving the mission of fisheries management involves three goals: habitat maintenance, fish conservation, and fish-use allocation. These goals are interrelated. In order for Albertans to enjoy the benefits that fish and fishing provide, there must be a sufficient fish resource available. Fish are a product of their habitat, and to produce fish there must be sufficient habitat available. Therefore, the habitat goal is the foundation of the fish conservation strategy and the provision of societal benefits such as recreation, economic returns and fish as wholesome food.

\subsection{Habitat Maintenance Goal}

The fish conservation strategy for Alberta endorses, as a working guideline, the federal Policy for the Management of Fish Habitat (Fisheries and Oceans Canada 1986). The objective of that policy is to achieve a net gain of habitat for fish resources. However, there are strict limitations on the potential to increase the productive capacity of habitats. Fish resources and fish habitats are finite, and every effort to avoid habitat loss or damage must be made. The Fisheries Management Division subscribes to the objective of no-net-loss of productive fish habitat. Protection of fish habitat is particularly important in Alberta, because there is a shortage of fish-producing habitat, especially in the settled areas of the province. Demand for fish exceeds the supply of fish. Sustaining the supply of fish through maintenance of habitat and habitat productivity is essential to balance the supply-demand relationship. The habitat maintenance goal is as follows:

\section{Habitat Maintenance Goal}

Restore and maintain the natural productive capacity of fish habitat, and where possible and appropriate, increase the amount of productive fish habitat.

Fish habitat is defined in the Fisheries Act as "spawning grounds and nursery, rearing, food supply and migration areas on which fish depend directly or indirectly in order to carry out their life processes (Section 34(1) Fisheries Act Canada RSC, 1985 c. F-14). " Equally important is the year-round need for an adequate supply of good-quality water. Formal authority for the fish habitat provisions of the Act continues to reside with the Minister of Fisheries and Oceans Canada.

\subsubsection{Habitat Maintenance Objectives}

\subsubsection{Fish Habitat Protection}

- Maintain the productive capacity of aquatic habitats to support healthy and diverse fish resources.

Resource stewardship--conserving the living spaces of our environment--is the responsibility of the general public and proponents of resource use, as well as government. In Alberta, the habitat program of the Fisheries Management Division uses the federal policy of no-net-loss of productive fish habitat as a working guideline for decision making. Proponents of work in and around water bodies are expected to incorporate mitigative measures in their development plans to meet the no-net-loss expectation. Where normal mitigative procedures can not eliminate fish habitat losses, then habitat 
compensation will be necessary to satisfy the objective of no-net-loss of productive fish habitat. Critical habitats for all life stages should be identified and protected. Physical damage to spawning sites and shoreline vegetation have to be minimized. Changes to watersheds that affect lake levels, stream flows, stream sedimentation, nutrient loading and contaminant levels in fish should be minimized. It is important to maintain unobstructed migration routes so fish have access to all their habitat requirements to sustain healthy populations.

Habitat as used in the context of the habitat maintenance goal also includes instream flow needs, water quality, fish health and ecosystem integrity. Sufficient year-round stream flows are essential for the maintenance of all life stages of fish populations. Contaminants can be carried in water and accumulate in fish without necessarily being lethal to the fish. However, these contaminants may have toxic effects on people or animals that consume the fish, and may impair fish reproduction. The Fisheries Management Division, in conjunction with Alberta Health, requires the development of a fish-quality monitoring strategy to measure fish contaminants and provide information to the public. The introduction of parasites or disease can contribute directly to fish mortality, or render fish in an unhealthy condition and vulnerable to mortality from natural environmental stresses or predation. Although fish parasites and diseases are seldom harmful to humans, infected fish are generally undesirable as food, or may affect animals that consume them. Introduction of undesirable aquatic species or the loss of desirable aquatic species can upset ecosystems and, among other things, result in the loss of fish production.

\subsubsection{Fish Habitat Rehabilitation}

- Alleviate or reverse adverse impacts on the productive capacity of habitats and repair damaged habitats to restore their productive capacity.

The proponents of development (natural resource, industrial, recreational, shoreline and instream work) need to rehabilitate the habitat they alter to restore productive capacity. Proponents should determine the extent and type of fish use and habitat base, incorporate appropriate habitat protection and compensation measures into development plans, monitor results of compensation actions and maintain habitat compensation features.

\subsubsection{Fish Habitat Development}

- Enhance fish habitats in areas where the production of fish resources can be increased, but maintain the aesthetic qualities of these sites.

Fish production can be increased by restructuring habitat, or altering fish species composition, in some situations and through the development of small reservoirs in areas where natural fish production is limited. However, careful planning and risk assessments are required as part of the decision-making process for the approval of such projects.

"Jo fully achieve the fish conservation strategy, water-use legislation and policy has to recognize fish as a user of water and incorporate the needs of fish into water resource management." 


\subsubsection{Integrated Resource Management}

Conservation of the fish resources can not be achieved through control of fish harvest alone--habitat maintenance is essential. Many aspects of habitat maintenance are not within the direct control of the Fisheries Management Division; therefore, Fisheries Management Division must act as an advocate to have the habitat maintenance goal of the fish conservation strategy integrated into the goals of other natural resource users. To fully achieve the fish conservation strategy, water-use legislation and policy has to recognize fish as a user of water and incorporate the needs of fish into water resource management. Habitat protection, habitat mitigation and water quality need to be treated by all resource users as essential components of resource management planning; e.g., by proponents of recreational development, timber harvest, agriculture and cattle grazing, petroleum and mineral exploration and extraction, and in particular, those involved with the use and control of the water resource and water quality.

\section{"Reduced fish production results from \\ the alteration or loss of habitat and the everharvest of fish."}

\subsection{Fish Conservation Goal}

The fish resources of Alberta have declined because of habitat losses and the overharvest of fish to the extent that it is not possible to fully satisfy current demand and meet future needs. As a consequence, managing for conservation first is necessary. In this context, conservation focuses on sufficient protection to ensure abundant fish populations and the appropriate use of only the surplus that is not required for population maintenance. Water body management of the whole fish community (ecosystem management) is a priority; however, species specific management is required to address concerns of endangered and threatened species or collapsed and vulnerable populations. Natural reproduction provides the most biologically-sound and cost-effective supply of fish. Fish stocking should only be used as a management tool in appropriate circumstances. The fish conservation goal is as follows:

Fish Conservation Goal

Restore and maintain the abundance, distribution and diversity of fish through natural reproduction.

Satisfying present demand and meeting future needs will require careful management of fish resources to ensure optimal reproduction of fish populations. Maintaining the variety of wild fish will allow full use of the many habitat types available, meet varying use expectations and maintain biological diversity of the fish community. 


\subsubsection{Fish Conservation Objectives}

\subsubsection{Fish Production Maintenance}

- Maintain the abundance and diversity of fish at the carrying capacity of the habitat.

\subsubsection{Fish Production Restoration}

- Restore diminished fish production to full production wherever possible.

\subsubsection{Fish Production Enhancement and Development}

- Enhance or develop new fish production wherever appropriate and possible.

Beyond habitat conservation, the first objective above involves managing fish harvest by managing human activities through regulations, and changing public attitude through information and education. Objectives two and three above involve bringing all publicly accessible waters with fish-producing capabilities into production where demand warrants it and it does not damage or compromise a sensitive species or ecosystem. In some cases, fish culture and fish stocking programs, with priority given to indigenous native species, are required.

\section{"Fish harvest must be regulated to match and not exceed the productive capacity of the habitat."}

\subsubsection{Fish Production Management}

Fish production is primarily controlled by the productive capacity of the habitat, the biological characteristics of the species and the species composition of the water body. However, fish harvest has historically been a major limiting factor on fish production. A high harvest level reduces population density, particularly by removing the older fish, which subsequently reduces a population's spawning capability. Wherever possible, recruitment of fish to the population will be accomplished through natural reproduction. Closure of spawning and rearing areas is often required to protect spawners, to reduce the disturbance of spawning fish, and to protect developing eggs and young fish.

Fish stocking has been, and will continue to be, considered in plans to re-establish fish where populations have collapsed, to establish new populations in suitable lakes, to provide trout fishing in areas where few other angling opportunities exist, and to provide diversity in angling experiences where appropriate. The primary intent of walleye stocking is to achieve self-sustaining populations, rather than maintenance of populations through continuous stocking. Fish introductions are guided by the documents $A$ Decision-Making Process for the Evaluation of Fish Introductions in Alberta (Berry and Stenton 1993) and Fish Stocking Process for Alberta (Natural Resources Service 1995).

Fish harvest must be regulated to match and not exceed the productive capacity of the habitat. The management of fishing mortality requires the development of appropriate regulations following the process outlined in the document Operational Guidelines for the Development of Fishery Regulations in Alberta (Berry 1994). 


\subsection{Fish-Use Allocation Goal}

Sportfishing in Alberta operates under an open-access policy and no limitation is placed on the number of licences issued. At present, youths under the age of 16 and Alberta residents aged 65 and older are not required to hold a licence. Dr. P. Pearse, in his review of sportfishing in Canada entitled Rising to the Challenge (Pearse 1988), suggests that demand management [in contrast to open access] should be considered as a tool to maintain a balanced supply-demand relationship. Restricting access, such as a limit to the number of licences available, will be used as a last resort in Alberta. In the future, however, special licensing systems that would limit the number of anglers at some water bodies may become necessary to sustain fish populations or to maintain the quality of the anglers' wilderness experiences.

\section{"The management of fisheries must follow a \\ policy that allows harvest only when a supply \\ of fish, beyond conservation needs, has been \\ proven available."}

The Alberta Fishery Regulations and the Fisheries Act of Canada operate as a set of rules restricting or prohibiting various fishing activities (restrictive code). A restrictive code means that all activities are legal until restricted or prohibited by regulations. Except as restricted by fishing regulations, fishermen may do the following: harvest any number of fish, and any species of fish; fish any waters; fish at all times of the year; and fish by any method. For the benefit of the resource and to ensure the primacy of conservation, fisheries management should operate under a permissive code--meaning no activity should be legal until made legal.

Resource conservation under an open-access policy and restrictive code is difficult and slow to be achieved. Resource overuse has to be demonstrated before support and public acceptance are gained for the establishment of new regulations. The time required to demonstrate overuse, gain public support and implement new regulations can result in further damage to fish populations. Because of the above, current management practices can fall short of conservation needs by allowing activities that overharvest fish. To be fully effective, the management of fisheries must follow a policy that allows harvest only when a supply of fish, beyond conservation needs, has been proven available.

Each water body, and its fish resources, should be examined from two perspectives: 1) the capability of the water body to produce fish, and 2) the public expectations for the fish and fisheries at the water body. Bringing both perspectives into harmony is a challenge in fisheries management that requires management of human activities for the benefit of the public, and more importantly, for the benefit of fish resources. 
Fish resources are finite and can only support limited harvest, which requires the following fish-use allocation goal:

Fish-use Allocation Goal

Allocate, through a public involvement process, the appropriate use or combination of uses of fish resources to achieve a range of optimal benefits that support the fish conservation goal.

\subsubsection{Fish-Use Allocation Objectives}

\subsubsection{Fish-Use Allocation Process}

- Allocate fish production, beyond conservation needs, to achieve the greatest overall benefits, using a fair process that involves stakeholders, identifies users' expectations, and provides a basis for setting benefit priorities.

The Fish and Wildlife Policy for Alberta (Fish and Wildlife Division 1982) stipulates that the interim allocation priorities will be in the following descending order, until supply and demand issues are addressed on a site-specific basis through the allocation process:

- Conservation of fish stocks,

- Subsistence fishing for Alberta's aboriginal people,

- Resident recreational use, and

- Commercial fishing and tourist angling.

In 1985, a statement of purpose was added to the Fisheries Act of Canada--to provide for the conservation and protection of fish and the waters frequented by fish. Arrangements for subsistence fishing by Alberta's aboriginal people were included in treaties and affirmed in the Constitution Act (1982). More recently, the Sparrow Decision of the Supreme Court of Canada (Regina v. Sparrow 1990), affirmed the limits that can be applied to subsistence fishing rights and established the primacy of conservation needs over all other uses. The Fish and Wildlife Policy for Alberta recognizes fish conservation as the first priority, and recognizes subsistence fishing by Alberta's aboriginal people.

Resident sport fishermen may fish anywhere they are entitled by their licenses. The Fish and Wildlife Policy for Alberta promotes recreational fishing as a legitimate activity from both recreational and ecological perspectives, and in addition to promoting rules to regulate activities, encourages the ethical conduct of fishermen. The policy also supports a viable commercial fishing industry.

The development of water body management plans, as outlined in the Water Body Management Strategy System (Berry 1994), is necessary for all major water bodies, particularly for commercially fished lakes, to address allocation issues. This involves lake-by-lake management. Different fish-use priorities for the harvestable supply may be established through the allocation process, within the constraints concerning conservation and subsistence fishing. At present, the process follows the above priority system and the document The Alberta Approach to Fisheries Allocation (Fish and Wildife 1988). An optimal allocation process has not been finalized and progress in this direction must continue. The first step in this process is the appropriate determination of the harvestable surplus that can be allocated to various uses. 


\subsubsection{Domestic Use}

- Provide for subsistence fishing within the constraints of fish conservation and legislative obligations.

In general, the priority for fish use after conservation is subsistence fishing for food by Alberta's aboriginal people. Management options concerning domestic fishing must be developed, with Native consultation, to conserve fish populations, to sustain subsistence fishing, and to maintain recreational and commercial fisheries.

\subsubsection{Recreational Use}

- Provide for recreational fishing under an open-access policy and place no limitation on the number of general licences issued, within the constraints of fish conservation and subsistence fishing.

Recreational fishing is managed in consultation with sportfishing organizations and the general public to:

- Maintain optimal recreational opportunities, and where some harvest can be permitted, place limits on harvest through selective regulations (size and catch limits) or catch-and-release regulations (zero limit);

- Ensure low mortality of released fish by using gear or capture method restrictions;

- Protect fish concentrated in critical habitats such as those used for spawning, wintering or migration by using gear or capture method restrictions, harvest regulations, or season closures; and

- Minimize impacts of competitive fishing events (tournaments and derbies) on fish populations and traditional recreational fishing through the development of policy, standards and controls regarding competitive fishing.

Tournaments and derbies combine sportfishing with commercial ventures and use fish resources for recreation and economic benefits. Tournaments and derbies tend to attract more anglers, than might otherwise visit, to the water bodies where they are held. These anglers can take a large portion of the total annual harvest of some species in just a few days. Most tournament organizers have adopted catch-and-release formats and implemented a variety of rules and practices to aid survival of released fish. Despite these efforts, high hooking mortalities can occur at some events. It may become necessary to restrict toumament activities at lakes where tournament loss of fish is excessive or where allocation issues arise.

At present, the Fisheries Management Division neither supports nor opposes competitive fishing and no controls are in place to restrict tournaments beyond the existing sportfishing regulations. The development of policy, standards and controls regarding tournaments and derbies, particularly involving an independent sanctioning body, are necessary.

\subsubsection{Commercial Use}

- Provide for commercial fishing opportunities within the constraints of fish conservation, subsistence fishing and recreational fishing.

At commercially fished lakes, setting minimal tolerance limits for species such as walleye, northern pike and lake trout in the commercial harvest will be the practice, and achieving compliance with these limits will be the objective. Restrictions, such as the timing of seasons, closed fishing zones and mesh 
size of gill nets, will be maintained to ensure that harvests are within limits. The use of selective gear types, such as trap nets, will be encouraged. Target species in commercial fisheries are generally lake whitefish and cisco (tullibee), and reasonable access to these species will be maintained. Commercial use of fish resources will be managed on a lake-by-lake basis in consultation with commercial fishermen and recreational users to:

- Recognize commercial fishing as a viable industry and a valid user of fish resources to meet the food-fish needs of the public, and where appropriate, the bait fish needs of anglers;

- Minimize harvest of species such as walleye, northern pike and lake trout below tolerance limits, while attempting to harvest the allocations of lake whitefish and cisco;

- Minimize commercial use of lakes having significant conservation concerns, marginal economic returns for target species or continued overharvest of species with tolerance limits; and

- Minimize fish-use conflicts that arise at various water bodies through frequent reviews using the allocation process.

To the above ends, the Fisheries Management Division has implemented the Fisheries Management Division Operating Guidelines Respecting Commercial Fishing (Natural Resources Service 1995).

\subsection{GUIDING PRINCIPLES IN FISHERIES MANAGEMENT}

There are several guiding principles that can assist in the implementation of the overall fish conservation strategy. They are:

\section{No net loss of the productive capacity of habitats.}

Every effort should be made to avoid habitat losses. If habitat losses are unavoidable, they should be balanced with habitat replacement.

The fish conservation strategy for Alberta uses the federal policy of, and guidelines for, no-net-loss of the productive habitat outlined in the document, Policy for the Management of Fish Habitat (Fisheries and Oceans Canada 1986). Formal authority for the fish habitat provisions continues to reside with the Minister of Fisheries and Oceans Canada.

As part of the fish conservation strategy, the role of proponents of development involves:

- Determining the extent and type of fish use and habitat base at sites of proposed development; and

- Incorporating appropriate habitat protection, mitigation and compensation measures, monitoring results of these measures and maintaining habitat mitigation and compensation features.

As part of the fish conservation strategy, the role of Fisheries Management Division involves:

- Identifying and maintaining adequate habitat protection guidelines to minimize impacts from physical disturbances of shoreline vegetation or disturbances within watersheds that may result in increased sediment loading, flood events, increased water temperatures, reduced stream flows, reduced lake levels, reduced water quality, reduced fish health, and disruption of ecosystems;

- Limiting instream and lake shore work in critical habitat areas to appropriate activities that can be fully mitigated; 
- Acting as an advocate of habitat maintenance and fish conservation, and working with proponents of resource development to integrate fish habitat needs into their resource management planning; and

- Providing public information/education concerning fish habitat needs and encouraging public involvement in habitat rehabilitation and development projects.

As part of the fish conservation strategy, the role of the public involves:

- Implementing, in conjunction with Fisheries Management Division, habitat enhancement projects to improve spawning and rearing areas, to remove or reduce the impacts of stream blockages, to improve stream bank cover and stability, and to maintain adequate lake levels with natural water-level fluctuations;

- Developing, in conjunction with Fisheries Management Division, guidelines for and the identification of water bodies that have wilderness values and characteristics that should be retained to ensure the quality of the wilderness experience; and

- Acting as an advocate of habitat maintenance and fish conservation, and encouraging the incorporation of fish habitat needs into resource development planning and water management.

\section{Fish populations are to be maintained by natural reproduction wherever possible.}

Natural reproduction is the most biologically sound and cost-effective way of maintaining fish populations and fish production.

Fish are self-reproducing if sufficient mature fish and suitable spawning and rearing habitat are present. Fish stocking can assist natural reproduction in some cases, and can maintain fish populations in others, but fish stocking is not an effective replacement for natural reproduction.

Maintenance of natural reproduction involves:

- Maintaining and improving spawning and rearing habitat, and fish access to this habitat;

- Maintaining sufficient numbers of mature adults in each fish population;

- Ensuring genetic integrity of fish populations, sub-populations and unique strains;

- Ensuring all fish introductions follow the document $A$ Decision-Making Process for the Evaluation of Fish Introductions in Alberta (Berry and Stenton 1993) and are consistent with Alberta's Fish Stocking Policy (Natural Resources Service 1995);

- Continuing to regulate the impact of aquaculture activities to ensure the safety of wild fish populations and fish habitat; and

- Developing a risk-analysis process to be used with the decision-making process for the evaluation of fish introductions, particularly where a proposal involves an exotic species.

3. The biological diversity of the fish fauna is to be maintained, and the depletion or extirpation of species, populations, sub-populations or unique strains must be avoided.

Any maintenance and protection strategy should include all fish species in order to maintain the biological diversity of the fish fauna.

This principle affects the habitat maintenance goal and the fish conservation goal. Although the overharvest of fish can quickly deplete a fish stock, habitat loss or damage can more permanently reduce or eliminate a fish population. 
Maintenance of natural biodiversity involves:

- Implementing preventative measures to reduce fish harvest or habitat losses before depletion occurs;

- Monitoring fish populations to determine their status, productive capabilities and potential problems;

- Avoiding the introduction of exotic species, including native species or strains not indigenous to the watershed;

- Avoiding the introduction of fish diseases and parasites; and

- Addressing the issue of authority concerning the removal of non-native (exotic) fish, nonindigenous native fish, nuisance fish and fish with diseases or parasites from private dugouts and reservoirs, and from public water bodies, when fish have been introduced illegally, have invaded from adjacent waters, are a risk to indigenous fish production, or are a hindrance to the establishment or maintenance of an important fishery.

\section{The management of the fisheries will be conducted on the basis of fundamental ecological principles and factual information.}

Good and timely information on fish stocks is fundamental to achieving habitat maintenance, fish conservation and fish-use allocation goals.

The capacity of various habitats for fish production, the conservation needs to perpetuate populations and the numbers that constitute a potential harvestable surplus need to be determined. Fish production varies annually and long-term trend information provides the best way to assess production, identify problems, evaluate management and make appropriate adjustments.

Achievement of this principle involves:

- Developing and maintaining adequate programs for gathering relevant information on fish stocks (including their number, growth, production rate, harvest rate and habitat conditions);

- Developing an information management system to handle the information and to provide pertinent and quick analysis in order to make appropriate and timely decisions;

- Allowing for years of low production in the calculation of the harvestable supply of a fish population to prevent overharvest;

- Giving fish conservation precedence over fish use, where adequate information on the harvestable supply is unavailable; and

- Monitoring fish populations for status and fish health, and reporting these results to the public.

\section{There should be public involvement and education in the fisheries management process.}

Greater public awareness and the involvement of a knowledgeable public are essential to increase public support for fisheries management.

Any attempt to regulate the harvest of fish will be ineffective without adequate compliance with regulations. At the present time a public review of any new or changed fishery legislation is required, by both the provincial and federal governments. Public involvement processes have to be improved. At the same time, the public should be made aware of the need for conservation. 
Public involvement in fisheries management is growing quickly. Volunteers have assisted in carrying out many habitat development and restoration projects. Volunteer programs often provide excellent opportunities for educating the public. Project funding from Fisheries Habitat Development and Fisheries Management Enhancement programs has provided many volunteer opportunities other than those provided by government programs. There is considerable enthusiasm among sportfishing groups for participating in this type of activity and it is becoming a part of the recreational experience. Many anglers have, through considerable cost and effort, become very knowledgeable about technical aspects of fisheries management and want to assist in fisheries management activities.

Public involvement in fisheries management requires:

- Maintaining the Standing Committee on Fisheries Information and Education to provide a coordinated approach to communication activities;

- Developing a range of communications tools to convey information on fish population status, fish biology, species management plans and water body management plans;

- Developing programs for public education about fish biology and resource management to augment the existing fishing education program;

- Including non-government organizations as participants in public information and education programs;

- Encouraging public involvement in fisheries management and habitat development programs;

- Obtaining public input as part of decision-making processes, and in program and project delivery processes; and

- Providing opportunities for public involvement and input to species and water body management plans.

\section{The "user-pays philosophy" should augment the financing of the stewardship and management of fish resources.}

The responsibility for financing the stewardship of fish resources must be shared by all, and supported directly by resource users such as fishermen, resource developers and industries.

Financial support for the management of fish resources and habitats on behalf of Albertans has to come from government through general revenue. The government is responsible for conserving these resources for all Albertans and for future generations. However, government financing should be augmented by fees and levies paid by users of the resources to help defray costs. The user-pays philosophy should apply to direct resource users such as anglers, and to indirect resource users such as industries that alter habitat. Industrial developers and other natural resource users should provide funding for research and impact-assessment studies, and provide mitigation and compensation for their impacts.

The user-pays philosophy includes:

- Continuing to collect, on behalf of the Alberta Conservation Association, a levy as part of the cost of the general Sportfishing Licence to help finance Fisheries Habitat Development and Fisheries Management Enhancement programs, and to help stock trout in municipal ponds to provide additional public fishing opportunities;

- Continuing to collect a small surcharge as part of the general Sportfishing Licence fee for the WISE Foundation to fund outdoor education activities; 
- Continuing to direct a portion of the Commercial Fishing Licence fee into a fund to help finance commercial fisheries management programs; and

- Investigating additional opportunities, such as funding from industries that impact fish resources, to study problems and to research methods that reduce impacts.

\section{Public access should be provided and maintained to waters producing publicly- owned fish.}

Unencumbered access to waters producing publicly-owned fish is a prerequisite to maintaining fish resources for public benefits.

Although water and the land under the water generally remain in public ownership, the lands surrounding water can be held in private ownership and public access may be limited or denied. In Alberta, there is a limited amount of fish-producing waters, so public access needs to be maintained to the waters containing publicly-owned fish. This will allow a maximum of fishproducing waters to meet demand and allow for maximum benefits. A number of government agencies can provide access development and maintenance within their mandates. The Fisheries Management Enhancement Program also has provisions to purchase land for public access to water bodies.

\subsection{MANAGEMENT ACHIEVEMENTS}

The Fisheries Management Division is actively working to achieve the objectives, goals and mission of this fish conservation strategy for Alberta. Since the implementation of the discussion paper, A Fish Conservation Strategy for Alberta, in 1990, several documents providing policies, guidelines and procedures have been completed (see reference section). Examples of these documents include guidelines for: regulation development, fish introduction decisions, the fish stocking process, water body management and commercial fishing. Also, a new process for scheduling commercial fishing seasons at the zone level was recently developed. Progress continues on the development of a watershed management system and an information management system. To date, completed species management plans include: Alberta's Bull Trout Management and Recovery Plan, Alberta's Golden Trout Management Plan, Alberta's Walleye Management and Recovery Plan, and Alberta's Lake Sturgeon Management Plan. Work is proceeding with additional species management and water body management plans, with input from the public and sportfishing organizations. The above documents are supported by numerous projects, biological studies and planning initiatives conducted by regional fisheries staff throughout the province.

Public involvement in fisheries management is important. Recent examples include the achievements of the Bull Trout Task Force, Walleye Task Force, Walleye Tournament Workshop; and the ongoing work of the Standing Committee on Fisheries Information and Education, and the Competitive Fishing Events Review Committee. Public involvement processes used by committees and groups have varied in format, but all have been very successful. 


\subsection{REFERENCES}

Berry, D.K. 1990. The Fish and Fisheries of Alberta: Facts and Figures. Alberta Forestry, Lands and Wildlife, Fish and Wildlife Division. $68 \mathrm{pp}$.

Berry, D.K. 1994. Water Body Management Strategy System. Alberta Environmental Protection, Fisheries Management Division. 33 pp.

Berry, D.K. 1994. Operational Guidelines for the Development of Fishery Regulations in Alberta. Alberta Environmental Protection, Fisheries Management Division. 24 pp.

Berry, D.K. 1994. Alberta's Bull Trout Management and Recovery Plan. Alberta Environmental Protection, Fisheries Management Division. 22 pp.

Berry, D.K. 1995. Alberta's Golden Trout Management Plan. Alberta Environmental Protection, Fisheries Management Division. 13 pp.

Berry, D.K. 1995. Alberta's Walleye Management and Recovery Plan. Alberta Environmental Protection, Fisheries Management Division. 32 pp.

Berry, D.K. 1996. Alberta's Lake Sturgeon Management Plan. Alberta Environmental Protection, Fisheries Management Division. 20 pp.

Berry, D.K., and C.E. Stenton. 1993. A Decision-Making Process for the Evaluation of Fish Introductions in Alberta. Alberta Environmental Protection, Fish and Wildlife Services. 29 pp.

Alberta Environmental Protection. 1996. Business Plan 1995-96 to 1997-98. Alberta Environmental Protection. $6 \mathrm{pp}$.

Fish and Wildlife Division. 1982. Fish and Wildlife Policy for Alberta. Alberta Energy and Natural Resources, Fish and Wildlife Division. $24 \mathrm{pp}$.

Fish and Wildlife Division. 1988. The Alberta Approach to Fisheries Allocation. Alberta Forestry, Lands and Wildlife, Fish and Wildlife Division. 5 pp.

Fish and Wildlife Division. 1990. A Fish Conservation Strategy for Alberta--discussion paper. Alberta Forestry, Lands and Wildlife, Fish and Wildlife Division. 33 pp.

Fisheries and Oceans. 1986. The Department of Fisheries and Oceans Policy for the Management of Fish Habitat. Ottawa: DFO/3209. 30 pp.

Natural Resources Service. 1996. Business Plan for Natural Resources Service. Alberta Environmental Protection, Natural Resources Service. 9 pp.

Natural Resources Service. 1995. Fisheries Management Division Operating Guidelines Respecting Commercial Fishing. Alberta Environmental Protection, Fisheries Management Division. 16 pp.

Natural Resources Service. 1995. Fish Stocking Process for Alberta. Alberta Environmental Protection, Fisheries Management Division. $19 \mathrm{pp}$.

Pearse, Dr. P. 1988. Rising to the Challenge. A New Policy for Canada's Freshwater Fisheries.

Report, Canadian Wildlife Federation. 180 pp.

Regina v. Sparrow. 1990. Supreme Court Report. Vol. 1. p. 1075. 


